\section{MANEJO DE LESIÓN ENDO- PERIODONTAL MEDIANTE TRATAMIENTO ENDODÓNTICO NO QUIRÚRGICO, REPORTE DEL CASO}

\author{
Dra. Elizabeth Aponte Bello ${ }^{1}$
}

Autor de correspondencia: draelizabethaponte@hotmail.com

\section{Resumen}

El adecuado tratamiento y pronóstico de las lesiones endoperiodontales dependen de un diagnóstico oportuno y preciso de los factores etiológicos para un correcto tratamiento.'

El objetivo de este artículo es demostrar la capacidad de reparación mediante la terapia endodóntica no quirúrgica. Caso clínico de paciente femenino de 53 años con periodontitis apical asintomática a nivel del incisivo lateral y primer premolar izquierdo superior con uso de técnica de medicación interconducto pasta de Hoshino ${ }^{3}$. Presentando evolución de cicatrización perirradicular en 12 meses tras el tratamiento endodóntico. Hallazgos confirmados bajo control radiográfico. Concluyendo que este tipo de casos de lesión combinada requieren un adecuado diagnóstico y protocolo endodontico para analizar si es requerido o no el tratamiento quirúrgico o no quirúrgico.

1 Especialista en Endodoncia, Universidad Santo Tomás, Colombia.

\section{MANAGEMENT OF ENDOPERIODONTAL LESION THROUGH NON-SURGICAL ENDODONTIC TREATMENT. CASE REPORT}

Fecha de recepción: Junio 2018

Fecha de aceptación: Agosto 2018

\begin{abstract}
Palabras clave: Lesión endoperiodontal, diagnóstico, pronóstico, reparación de lesión, medicación interconducto.
\end{abstract}

\section{Abstract}

The adequate treatment and prognosis of endoperiodontal lesions depend on a timely and accurate diagnosis of the etiological factors for a correct treatment.

The aim of this article is demonstrate the repair capacity through therapy non-surgical endodontic case of a 53-year-old female patient with periodontitis apical asymptomatic at the level of the lateral and first upper left premolar with use of technique of medication root canal triple antibiotic paste Hoshino, with healing evolution periradicular in 12 months after endodontic treatment. Findings confirmed under control radiographic concluding that this type of combined injury cases diagnosis and endodontic protocol to analyze whether surgical treatment is required or not or non-surgical. 
Keywords: Endoperiodontal injury, diagnosis, prognosis, injury repair, medication root canal, triple antibiotic.

\section{Introducción}

Simring y Goldberg, en 1964, fueron los primeros en describir la relación entre la enfermedad periodontal y pulpar. ${ }^{4}$ Existe una unidad biológica compuesta entre la parte dinámica de la pulpa y el periodonto la cual debe estar en buen estado en beneficio de los tejidos dentales y tejidos de soporte. ${ }^{5}$ Las lesiones endoperiodontales tienen una interconexión anatómica y vascular entre la pulpa y el periodonto. ${ }^{4}$ Por último, el foramen apical es la ruta principal de comunicación de bacterias y productos inflamatorios existentes en los conductos radiculares pueden extenderse a los tejidos periapicales, causando una respuesta inflamatoria local que puede ir acompañada de reabsorción ósea y radicular.

\section{Clasificación de lesiones endoperiodontales:}

Relaciones patológicas (Guldener \& Langeland). ${ }^{4-5}$

A. Lesión endodóntica-periodontal: Pulpa necrótica que precede a los cambios periodontales.

B. Lesión periodontal-endodóntica: Presencia de bolsa periodontal con infección bacteriana, pérdida de inserción y exposición radicular.

C. Lesiones combinadas: compromiso Endo-Perio.

\section{Clasificación de Simon: ${ }^{6}$}

A. Lesión Endodóntica primaria: Respuesta ante fracasos endodonticos. Presentando exacerbación con signo clínico de fistula.

B. Lesión endodóntica primaria con compromiso periodontal secundario: Lesión endodóntica no tratada evolucionando a lesión periodontal secundaria.

C. Lesión periodontal primaria: Lesiones localizadas y generalizadas con pruebas de vitalidad positiva del tejido pulpar.

D. Lesión periodontal primaria con compromiso endodóntico secundario: Continuidad de bolsa periodontal hasta el límite apical afectando el tejido pulpar.

F. Lesión periodontal y pulpar verdadero.

Cuando se presenta una lesión endoperiodontal se debe buscar el origen de la infección para obtener diagnóstico diferencial entre enfermedad endodóntica, periodontal o combinada. ${ }^{6}$

\section{CASO CLÍNICO}

Paciente de género femenino 53 años de edad remitido a la especialidad de endodoncia para valoración del incisivo lateral y primer premolar superior izquierdo. A la anamnesis la paciente no refiere trauma dentoalveolar ni tratamiento de ortodoncia. Refiere dolor muy leve a la presión sin presentar inflamación. Al examen clínico intraoral leve aumento de volumen de la mucosa del incisivo lateral y primer premolar superior izquierdo, no presencia de tracto sinuoso, pruebas de sensibilidad pulpar negativas y sin cambio de color de estructuras coronales, pruebas de percusióny palpación positivas. Al examen periodontal presenta profundidades sondeables de $7 \mathrm{~mm}$ en distal del incisivo lateral y 8 $\mathrm{mm}$ en mesial-distal del primer premolar, y movilidad grado III. Al examen radiográfico, se observaba imagen radiolúcida periapical que continua con el ligamento periodontal con compromiso en tejidos perirradiculares del incisivo lateral y primer premolar superior izquierdo, reabsorción externa apical y perdida de luz de conducto a nivel del lateral. ${ }^{\mathrm{FIG}} 1$

Se ordena realizar una tomografía volumétrica digital. Se procedió a evaluar la tomografía computarizada digital de alta resolución a partir del software de visualización de imágenes en 3D (i-Dixel 2.0 - One Volume Viewer, Accuitomo 80 - J. Morita Mfg. Corp., Kyoto, Japón). Se pudo observar la extensión real de la lesión. ${ }^{\text {IIG. 1a }}$

Se estableció un diagnóstico de periodontitis apical asintomática y lesión endoperiodontal combinada. Se inicia intervención endodóntica. Inicialmente en la primera cita bajo protocolo anestésico y aislamiento absoluto del campo operatorio, se procede a realizar 
apertura mínimamente invasiva con acceso a cámara del incisivo lateral y primer premolar con exudado intracameral instrumentación para ambientación intraradicular se irrigó profusamente con hipoclorito de sodio $(\mathrm{NaOCl})$ al 5.25\%, Se establece dejar medicación intraconducto a base de la pasta de 3 Mix-Mp (Metronidazol,Ciprofloxacina,Cefalexina) relación 1:1:1 con vehículo agua destilada dentro del conducto radicular sin dejar en contacto con la cámara y bajo la línea amelo cementaría. ${ }^{7}$ Con uso de técnica modificada de Novel y sellando temporalmente acceso de conducto para realizar grabado-acido en cámara y evitar la adherencia a la superficie coronal y pigmentación de parte de la pasta triantibiotica. ${ }^{8}$

Se remite a la especialidad de periodoncia para manejo de raspado y alisado radicular. Segunda cita después de 15 días se procede a irrigar con ( $\mathrm{NaOCl})$ al 5.25\% reinstrumentación y medicación intraconducto 3 Mix-Mp. Tercera cita después de 3 semanas preparación biomecánica, irrigación con hipoclorito de sodio $(\mathrm{NaOCl})$ al 5.25\%, activación ultrasónica final alternando $10 \mathrm{~mL}$ de $\mathrm{NaOCl}$ activado por 30 segundos seguido de $10 \mathrm{ml}$ de EDTA 17\% activado por 30 segundos y nuevamente $10 \mathrm{~mL}$ de $\mathrm{NaOCl}$ activado por 30 segundos. Verificación punta de papel (Dentsply Maillefer) de canales radiculares libres de exudado y se realiza obturación con técnica de compactación vertical. Cemento de elección fue Sealapex (KerrDental) se realiza obturación definitiva. Tratamiento endodontico finalizado del incisivo lateral y premolar superior izquierdo ${ }^{\mathrm{FIG} .} 2$. En la evaluación clínica, después de 3 meses $^{\mathrm{FIG}} 3,7$ meses FIG.4, y a los 12 meses. ${ }^{\text {FIG. } 6}$ En la cita control no presenta sintomatología, ausencia de fístula o edema vestibular y los sondajes periodontales dentro de valores normales entre 1 y $3 \mathrm{~mm}$. Buena evolución de inserción de tejidos periodontales y disminución de movilidad dental.

Radiográficamente se puede observar ausencia de áreas radiolúcidas con reparación ósea periapical y ausencia de pérdida ósea circundante.
Fig.1 Rx. Inicial lateral y primer premolar superior izquierdo.

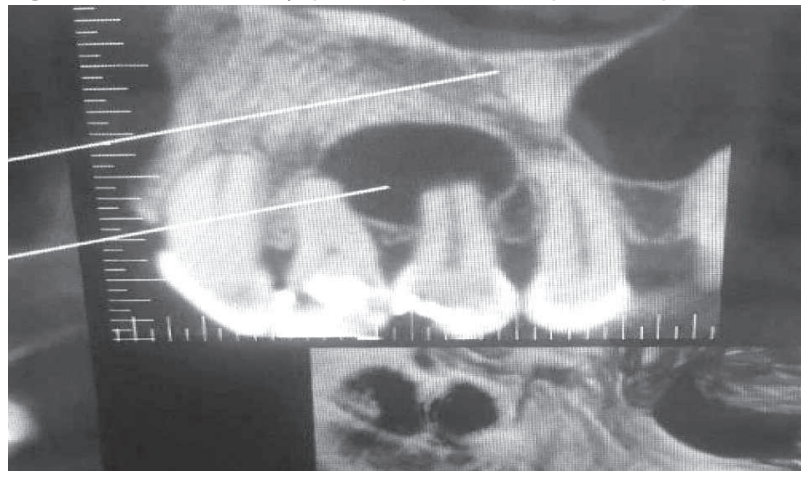

a Tomografía CBCT

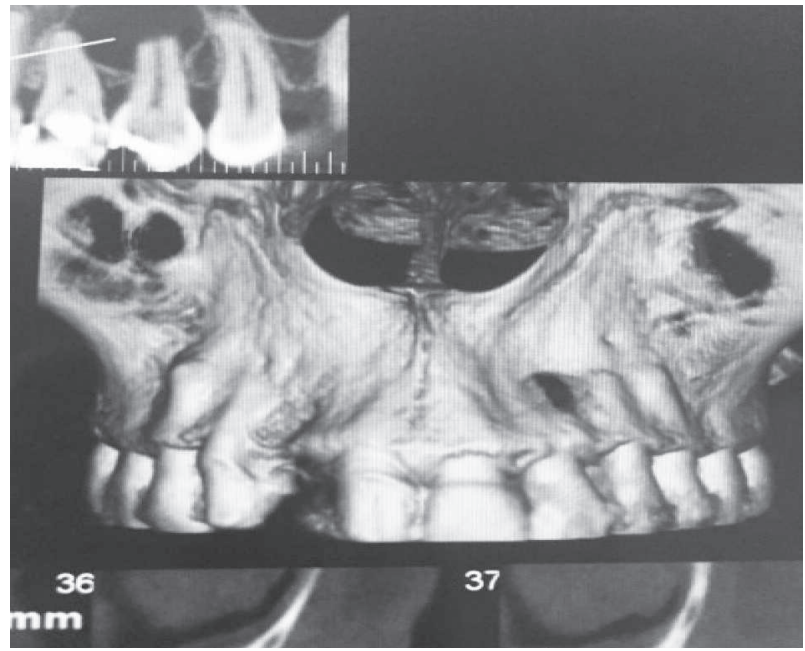

Fig.2 Rx. Postratamiento Endo-Perio.

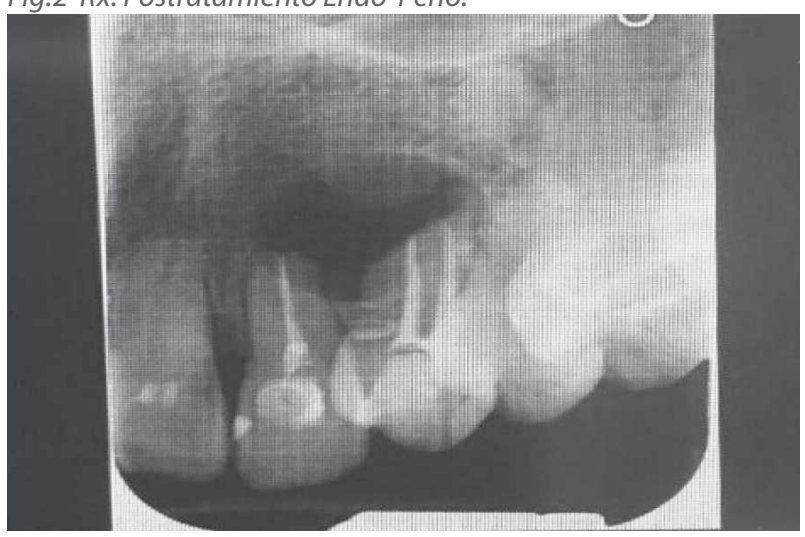

Fig.3 Rx.Control 3 meses.

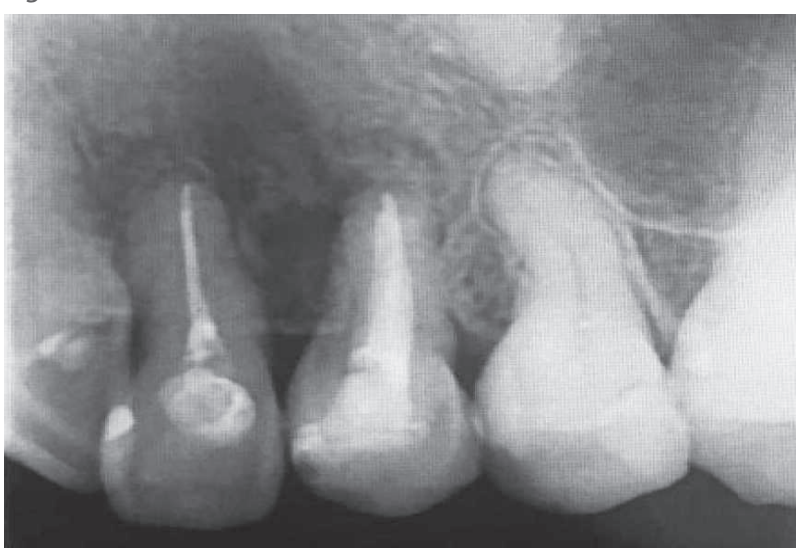


Fig.4 Rx.Control 7 meses.

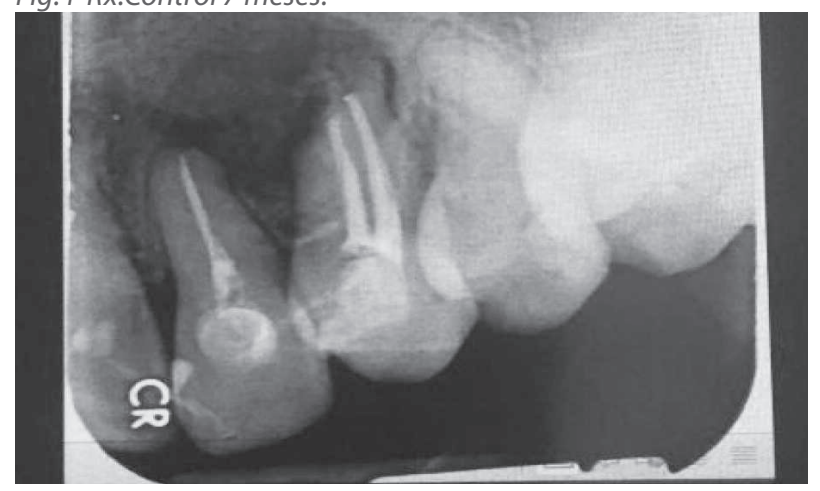

aControl 12 meses.

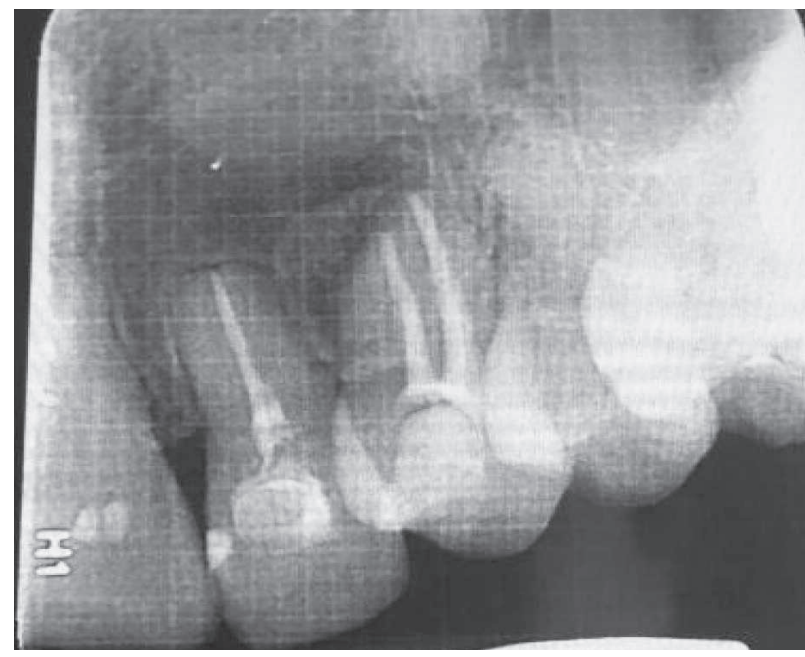

\section{Discusión}

Sato y Hoshino observaron el potencial de la pasta triantibiotica para eliminar las bacterias en las capas más profundas del conducto radicular ${ }^{9}$. Esta pasta tiene la capacidad de atravesar la dentina actuando así sobre la lesión inhibiendo la presencia de microorganismos en la lesión periapical 10,11, modular la inflamación de los tejidos peria-picales, responsables del proceso de reparación, neutralizar los restos orgánicos presentes y ayudar a secar los conductos húmedos persistentes de exudado por lo cual la elección de la pasta 3Mix-Mp, fue la más consistente para este caso clínico. Este reporte de caso obtuvo resultados muy satisfactorios con disminución de la lesión perirradicular y tejidos periodontales.

\section{Conclusión}

La combinación de irrigación y desinfección con el protocolo de pasta triple antibiótica permite la regeneración de las lesiones periapicales en la terapia de endodoncia no quirúrgica endo-periodontal.

El manejo de antibióticos contrarresta la diversidad bacteriana así como evitar las bacterias resistentes. Las lesiones endo-periodontales representan con frecuencia un reto de diagnóstico.

La tomografía computarizada de haz cónico (TCHC) y el uso de magnificación son herramientas fundamentales, tanto para la detección de la causa en estas lesiones, como para su tratamiento.

\section{Bibliografía}

1. Cohen S, Burns R. Endodoncia. Los caminos de la pulpa. $4^{\mathrm{a}}$ ed. Buenos Aires. Argentina: Médica Panamericana; 1991

2. Simring $M$, Goldberg $M$. The pulpal pocket approach: retrograde periodontitis. J Periodontol. 1964; 35: 22-48.

3. Hoshino $\mathrm{E}$, Kurihara-Ando N. In vitro antibacterial susceptibility of bacteria taken from infected root dentine to a mixture of ciprofloxacin, metronidazole and minocyclina. Int Endod J. 1996; 29: 125-30

4. Gunnar, Bergenholtz, Preben, Horsted-Bindslev, Claes, Reit. (2011). Endodoncia. (Segunda Edición) Rostein I. \& H. Simon, J. (2006). The endo-perio lesion: A critical appraisal of the disease condition.

5. Carranza, F. Klokkevold, P. Takei, H., Newman, M. (2012). Carranzas clinical Periodontology, (Eleventh Edition)

6. Jaquez Bairan, E. (2000). Lesiones endoperiodontales. Foce, E. Endo-periodontal lesions.

7. Kim E, Song JS, Jung IY, Lee SJ, Kim S. Prospective clinical study evaluating endodontic microsurgery outcomes for cases with lesions of endodontic origin compared with cases with lesions of combined periodontal-endodontic origin. J Endod. 2008; 34: 546-551.

8. Sato I,Ando-Kurihara N, Kota K,Iwaku M,Hoshino E. Steriliza-tion of infected root-canal dentine by topical application of a mixture of ciproxacin, metronidazole and minocycline in situ. Int En-dod J.1996 Mar;29(2):118-24.

9. Varalakshmi R Parasuraman, Banker Sharadchandra Muljibhai. "3Mix- MP in Endodontics - An overview". Journal of Dental and Medical Sciences (JDMS). 2012; 3(1):36-45

10. Hoshino E. Tamanna. Suscepti-bility of enterococcus faecalis to a combination of antibacterial drugs (3Mix) in vitro. J. Oral Biosci. 2005; 47(4):315-320

11. Tratamiento de una periodontitis apical. Available from: https://www.researchgate.net/publication/307143422_Tratamiento_de_una_periodontitis_apical_cronica_reagudizada_ con_pasta_3_Mix-MP [accessed Jun 18 2018]. 